\title{
Investigation on optical, electrical and etching properties of 2- aminopyridinium 4-aminobenzoate: A phase matchable organic single crystal for optoelectronic device applications
}

\author{
L. Chandra ${ }^{1}$, J. Chandrasekaran ${ }^{2, *}$, K. Perumal $^{2}$, B. Babu ${ }^{2}$, V. Jayaramakrishnan ${ }^{3}$ \\ ${ }^{1}$ Department of Physics, Chikkaiah Naicker College, Erode-641 020, Tamil Nadu, India \\ ${ }^{2}$ Department of Physics, Sri Ramakrishna Mission Vidyalaya College of Arts and Science, Coimbatore-641 020, \\ Tamil Nadu, India \\ ${ }^{3}$ Centro de Investigaciones en Optica, Loma del Bosque 115, León, Guanajuato-37150, México
}

\begin{abstract}
NLO active 2-aminopyridinium 4-aminobenzoate (APAB) single crystals were successfully grown by the standard slow evaporation technique. The crystallinity of the grown crystals was analyzed through X-ray diffraction (XRD) measurements. Fourier transform infrared (FT-IR) spectroscopic studies were also performed for the identification of different modes present in the compound. The UV-Vis absorption and transmittance spectra were recorded for the grown crystal and the optical band gap was calculated. Birefringence and etching studies were also carried out. The dielectric study showed that the dielectric constant decreased with an increase in frequency. The photoconductivity study revealed its positive photoconducting nature. Theoretical HOMO LUMO investigations were also made for the crystal. The relative SHG efficiency of the material was investigated by the Kurtz and Perry powder technique. The phase matching property of the crystal was studied through the SHG dependence of average particle sizes.
\end{abstract}

Keywords: crystal growth; NLO; birefringence; etching; phase matching

(C) Wroclaw University of Science and Technology.

\section{Introduction}

Organic nonlinear optical crystals have been prominently investigated in the recent years owing to their high nonlinearity and rapid response to electro-optic effect. Significant interests were shown in the design and development of new NLO materials because of their vital applications in the generation of higher harmonic frequencies, frequency mixing, self-focusing, electro-optic modulation, optical parametric oscillator, etc. [1-4]. Generally, $\pi$-conjugated systems, linking the donor and acceptor, show a large NLO response. Acentric molecules consisting of highly delocalized $\pi$-electron systems interacting with suitably substituted electron donor and acceptor groups exhibit a high value of second order polarizability [5-7]. Hence, they are projected as forefront candidates for the fundamental and applied investigations. In this work,

*E-mail: jchandaravind@yahoo.com an attempt has been made to locate a class of organic NLO crystalline materials involving charge transfer mechanism [8]. 2-aminopyridine is one such $\pi$-donor-acceptor molecular compound in which 4-aminobenzoic acid gives one of its proton $\left(\mathrm{H}^{+}\right)$to the 2-aminopyridine. Hence, the asymmetric system consists of a protonated 2-aminopyridine mono-ionized with 4-aminobenzoic acid. Previously, Arumanayagam et al. [9] performed optical transmittance, band gap, refractive index, optical conductivity, dielectric and powder SHG studies of these crystals. In this manuscript, additionally to those studies, we present the first investigation of the powder XRD, FT-IR, birefringence, photoconductivity, etching and phase matching properties of APAB.

\section{Experimental}

\subsection{Material synthesis}

Pure specimens of 2-aminopyridine and 4-aminobenzoic acid were used without further 
purification for material synthesis. The two reactants were dissolved separately with 1:1 molar ratio in methanol and mixed together. The resulting solution was stirred well for about 30 minutes. The obtained microcrystalline product was filtered and then purified by repeated recrystallization process in methanol. The recrystallized compound was used for single crystal growth by the solvent evaporation technique.

\subsection{Crystal growth}

It is easy to grow APAB single crystals of optical quality using a standard slow evaporation technique. A saturated solution of APAB in methanol was prepared and stirred well for about an hour to dissolve the material completely. The solution was then filtered through a quantitative Whatman ${ }^{\mathrm{TM}}$ Grade 41 filter paper to remove the suspended impurities. The beaker containing the filtrate was covered using a thin polythene sheet to prevent quick evaporation. The perforations were made to regulate the evaporation. The beaker was kept aside unperturbed in an atmosphere which is most suitable for the growth of single crystals. Proper care was taken to minimize the mechanical disturbance and the temperature fluctuations. In a normal growth period of 10 days, single crystals of the title material were harvested and subjected to different characterization techniques. The quality of the grown crystal is shown in the Fig. 1.

\section{Results and discussion}

\subsection{X-ray diffraction analysis}

The cell parameters of the APAB crystals were estimated by the single crystal X-ray diffraction analysis using an Oxford Diffraction Xcalibur with a sapphire CCD detector and an enhanced diffractometer $(\mathrm{MoK} \alpha$ radiation, graphite monochromator; $\lambda=0.71073 \AA$ ). The cell parameters obtained are $\mathrm{a}=19.1495(5) \AA, \mathrm{b}=5.7453(2) \AA$, $\mathrm{c}=10.4776(4) \AA$, and $\mathrm{a}=\mathrm{b}=\mathrm{c}=90^{\circ}$. The grown crystal belongs to the orthorhombic crystal system with the space group Pca2 $2_{1}$. It is observed that the lattice parameter values and cell volume of APAB are in good agreement with the earlier

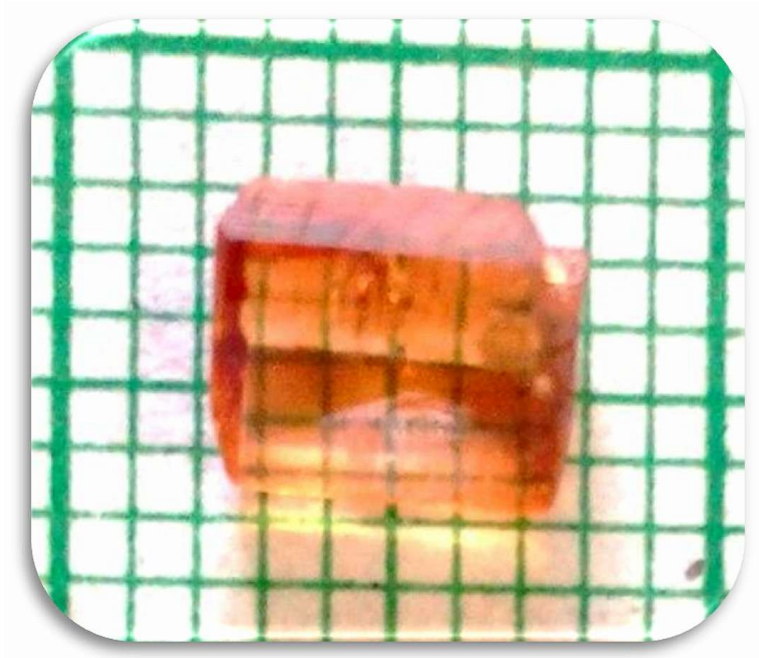

Fig. 1. As-grown APAB single crystal.

reported values [10]. The powder X-ray spectrum of APAB was carried out using X'Pert-Pro Xray diffractometer by employing $\mathrm{CuK} \alpha$ radiation. The recorded spectrum is depicted in Fig. 2. In the powder X-ray diffraction pattern, the presence of prominent Bragg peaks at specific $2 \theta$ angles confirms the perfect crystalline nature of the APAB crystal.

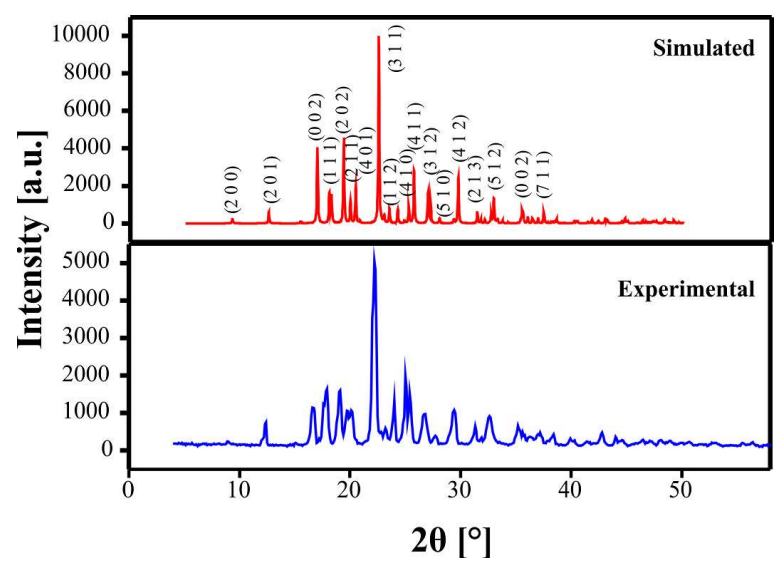

Fig. 2. Powder XRD pattern of APAB.

\subsection{FT-IR analysis}

The middle infra-red spectrum of the grown APAB crystal was recorded using a JASCO FT-IR 460 Plus spectrometer by the $\mathrm{KBr}$ pellet technique in the wavelength range of $400 \mathrm{~cm}^{-1}$ to $4000 \mathrm{~cm}^{-1}$. 
The spectrum depicted in Fig. 3 shows the presence of characteristic absorption bands owing to the varied force constants in the donor and acceptor species on account of the prevalent charge transfer mechanism. This makes the crystals more ionic than the other organic crystals.

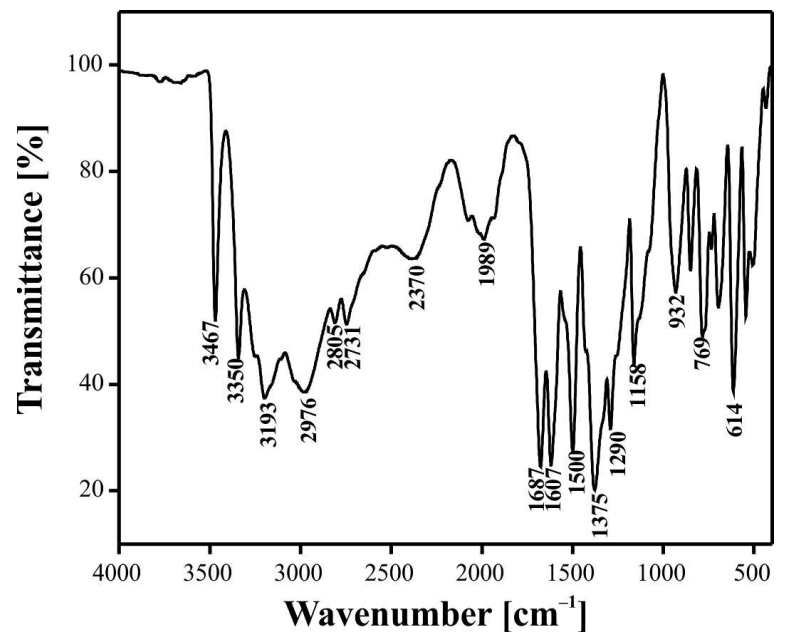

Fig. 3. FT-IR spectrum of APAB crystal.

Normally, in an acid base reaction, a proton transfer from the acceptor (acid) to the donor (base) is expected to occur. The bands at $3467 \mathrm{~cm}^{-1}$ and $3350 \mathrm{~cm}^{-1}$ are due to the $\mathrm{O}-\mathrm{H}$ stretching vibration. The peaks at $3193 \mathrm{~cm}^{-1}$ and $2976 \mathrm{~cm}^{-1}$ are attributed to the $\mathrm{NH}_{2}$ stretching frequency in amine functionality. The $\mathrm{C}=\mathrm{O}$ stretching vibration is observed at $1687 \mathrm{~cm}^{-1}$ and $1607 \mathrm{~cm}^{-1}$. The absorption observed at $1500 \mathrm{~cm}^{-1}$ is due to $\mathrm{COO}^{-}$ stretching vibration. The $\mathrm{C}-\mathrm{H}$ rocking vibration is observed at $1375 \mathrm{~cm}^{-1}$. The $\mathrm{C}-\mathrm{N}$ stretching vibration is attributed to the peak at $1290 \mathrm{~cm}^{-1}$. The absorption observed at $1158 \mathrm{~cm}^{-1}$ is due to $\mathrm{C}-\mathrm{O}$ stretching vibration. The $\mathrm{OH}$ bending vibration is observed at $932 \mathrm{~cm}^{-1}$. The absorption observed at $769 \mathrm{~cm}^{-1}$ is due to $\mathrm{COO}^{-}$scissoring vibration. The sharp absorption band at $641 \mathrm{~cm}^{-1}$ is attributed to aromatic $\mathrm{O}-\mathrm{H}$ out-of-plane bending vibration.

\subsection{UV-Vis absorption spectrum}

The UV-Vis absorption spectrum of the APAB crystal recorded using the SYSTRONICS DOUBLE BEAM UV-Vis spectrophotometer in the range of $200 \mathrm{~nm}$ to $1100 \mathrm{~nm}$ gives limited information about the structure of the molecule because the absorption of UV and visible light involves the promotion of an electron in $\sigma$ and $\pi$ orbitals from the ground state to higher energy states.
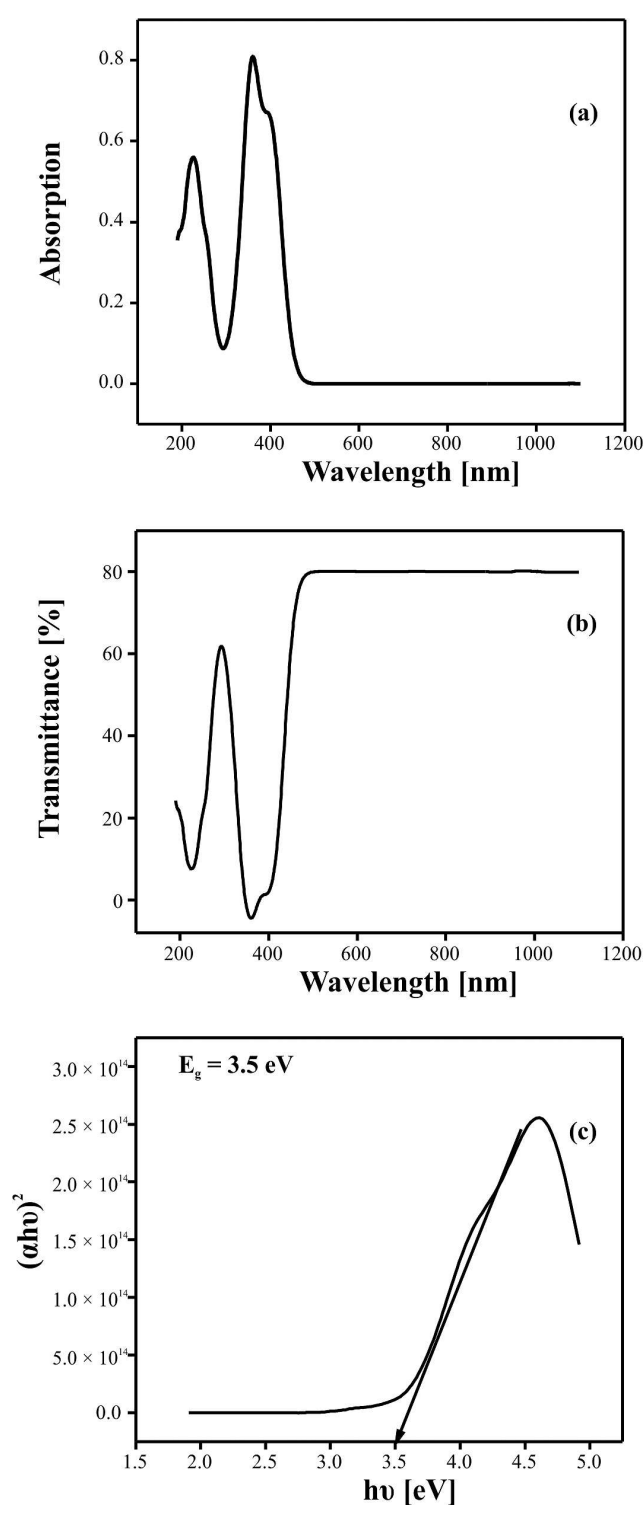

Fig. 4. (a) UV absorption spectrum of APAB crystal; (b) UV transmission spectrum of APAB crystal;

(c) The plot of variation of $(\alpha h v)^{2}$ versus hv.

The electronic absorption spectrum of the APAB crystal is depicted in Fig. 4a. At $226 \mathrm{~nm}$ and $358 \mathrm{~nm}$, sharp rises in absorption to the maximum are observed in the ultraviolet region of the spectrum, wherein the strong absorption band at around 
$358 \mathrm{~nm}$ can be attributed to the charge transfer transition. The longer wavelength absorption band arises owing to the promotion of an electron from the highest occupied molecular orbital to the lowest unoccupied molecular orbital. This in turn confirms the formation of complex molecules owing to the transfer of charges.

\subsection{UV-Vis transmission spectrum}

The transmission spectrum plays a vital role in identifying the potential of an NLO material. A given NLO material can be of utility only if it has a wide transparency window. The spectrum is shown in Fig. 4b. The polished APAB crystals with the size of $4 \mathrm{~mm} \times 4 \mathrm{~mm} \times 1.2 \mathrm{~mm}$ were chosen and subjected to transmittance studies. The grown crystal has no absorption beyond the wavelength $400 \mathrm{~nm}$ (visible region). Hence, this illustrates the suitability of the crystal for second harmonic generation and also for various optical applications $[11,12]$. The dependence of the optical absorption coefficient on the photon energy helps to study the band structure and the type of transition of electrons [13].

The optical absorption coefficient $(\alpha)$ was calculated from the transmittance using the following relation:

$$
\alpha=-\frac{1}{t} \ln \left(\frac{1}{T}\right)
$$

where $\mathrm{T}$ is the transmittance and $\mathrm{t}$ is the thickness of the sample.

Owing to the direct band gap, the crystal under study has an absorption coefficient $(\alpha)$ obeying the following relation for high photon energies $(\mathrm{hv})$ :

$$
\alpha=\frac{A\left(h v-E_{g}\right)^{\frac{1}{2}}}{h v}
$$

where $E_{g}$ is the optical band gap of the crystal and $\mathrm{A}$ is a constant. The plot of variation of $(\alpha \mathrm{h} v)^{2}$ versus hv is shown in Fig. 4c. Eg is evaluated by the extrapolation of the linear part of the plot [14]. The optical band gap energy is found to be $3.5 \mathrm{eV}$.

\subsection{Birefringence studies}

The precise measurement of birefringence properties has become increasingly significant in

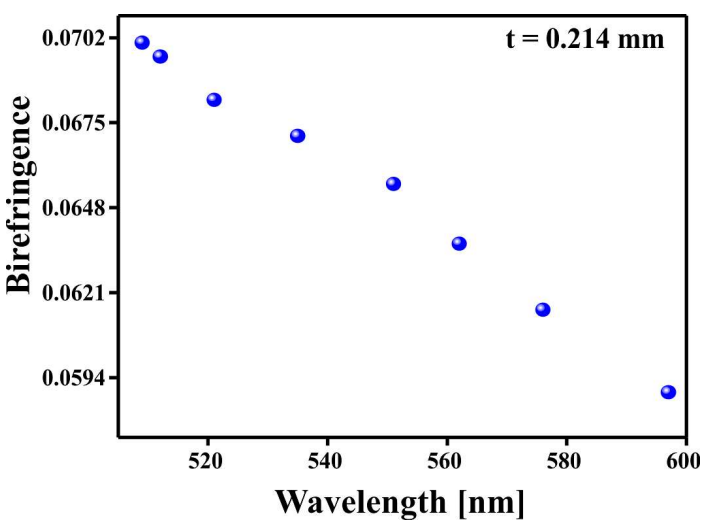

Fig. 5. The variation of birefringence with wavelength.

a number of technical applications. For the past few decades physicists have been interested in precise measurement of the principle refractive index and the optical double refraction (birefringence) along their dispersion with wavelength, which plays a vital role in the linear and nonlinear optics. The birefringence dispersion seems to play an important role in many applications of crystals, including retardation plates, polarizers and optical modulators [15]. An optically polished single crystal of APAB was subjected to birefringence measurements using the modified channeled spectrum (MCS) method with a halogen lamp as a source. The values of the birefringence have been calculated by finding the absolute fringe order for a particular wavelength and computed using the relation: $\Delta \mathrm{n}=\mathrm{k} \lambda / \mathrm{t}$, where $\lambda$ is the wavelength in $\mathrm{nm}, \mathrm{t}$, the thickness of the crystal in $\mathrm{mm}$ and $\mathrm{k}$, the fringe order. The graph showing the variation of birefringence $(\Delta \mathrm{n})$ against wavelength $(\lambda)$ is presented in Fig. 5. It is seen that the values of the birefringence of the SEST grown APAB crystal $(0.214 \mathrm{~mm}$ thickness) lie between 0.058942 and 0.070058 in the wavelength range of $510 \mathrm{~nm}$ to $600 \mathrm{~nm}$. Such a nominal variation of birefringence over a wide range of wavelength shows that these crystals may be useful in second harmonic generation (SHG) and optoelectronic devices.

\subsection{Dielectric studies}

Dielectric studies of the grown crystals were taken using Hioki LCR HiTESTER (Model 

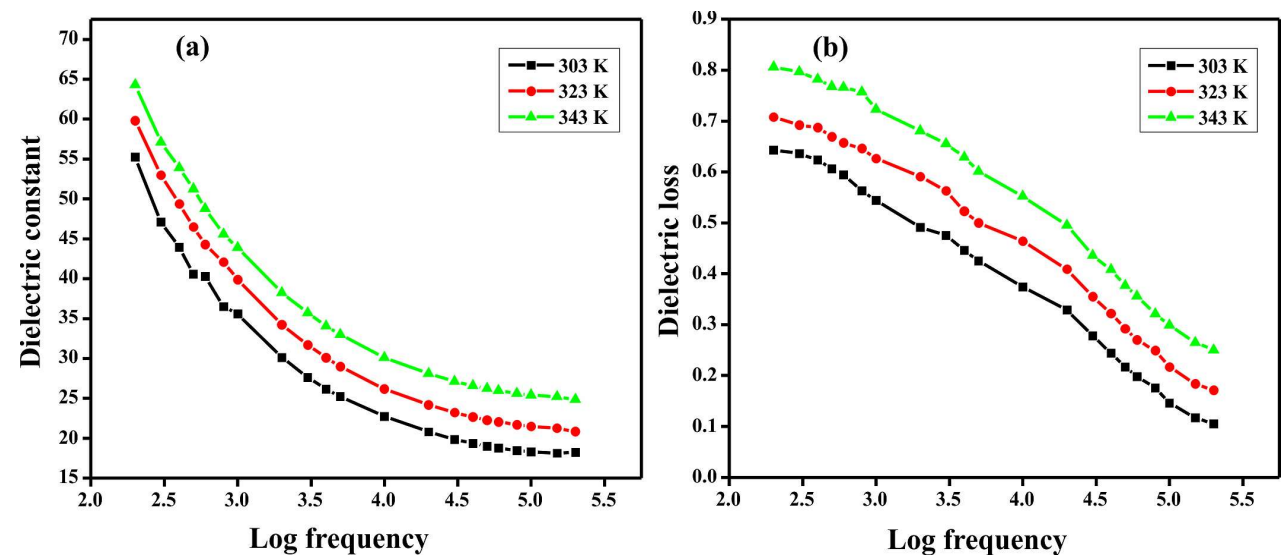

Fig. 6. (a) The plot of dielectric constant $\left(\epsilon_{\mathrm{r}}\right)$ versus log frequency; (b) the variation of dielectric loss with $\log$ frequency.

3532-50). The measurements were carried out in the temperature ranging from $303 \mathrm{~K}$ to $343 \mathrm{~K}$.

Fig. 6a shows the plot of dielectric constant $\left(\epsilon_{\mathrm{r}}\right)$ versus $\log$ frequency. The dielectric constant has higher values in the lower frequency region and then it decreases with the increasing frequency. The very high values of the dielectric constant at low frequencies may be due to the presence of space charge, orientation, electronic and ionic polarizations. The low value of the dielectric constant at higher frequencies may be due to the loss of these polarizations gradually. At high frequency, the defects have no longer enough time to rearrange in response to the applied voltage; hence, the capacitance decreases. In accordance with the Miller rule, the lower value of the dielectric constant at higher frequencies is a suitable parameter for the enhancement of the SHG coefficient [16]. The variation of dielectric loss with log frequency is shown in Fig. 6b. The characteristics of low dielectric loss at high frequencies for a given sample suggest that the sample possesses an enhanced optical quality with lesser defects and this parameter plays a vital role in the fabrication of nonlinear optical devices [17].

Compared to previous results $\left(\epsilon_{\mathrm{r}}\right.$ and $\tan \delta$ at $308 \mathrm{~K}$ are 120 and 2.1) [9] both the dielectric constant and dielectric loss $\left(\epsilon_{\mathrm{r}}\right.$ and $\tan \delta$ at $303 \mathrm{~K}$ are 55 and 0.62 ) in the present study were found to be low which confirms the purity of the crystal.

\subsection{Photoconductivity studies}

Photoconductivity measurements for the grown APAB crystals were taken by Keithley Model 6517B Electrometer. Photoconductivity is caused by the absorption of photons, leading to the creation of free charge particles in the conduction band and/or in the valence band. The mechanisms of band-to-band transitions, impurity levels to band edge transitions, ionization of donors, or deep level (located in the valence band) to conduction band transitions contribute to the photoconduction [18]. The photoconductivity response of the grown APAB crystal is depicted in Fig. 7. It is observed that both the dark and the photocurrents increase linearly with the applied electric field. Here, the photocurrent is found to be always greater than the dark current. From this it is concluded that the APAB single crystal exhibits a positive photoconductivity. The phenomenon of positive conductivity can be attributed to the generation of mobile charge carriers by the absorption of photons [19].

\subsection{Etching studies}

Some of the important features of the crystal surfaces such as hillocks growth, spirals and grain boundaries are essential to study the microstructural imperfections of the crystals. Etching study is an important tool for the identification of crystal defects. The best etching action was 


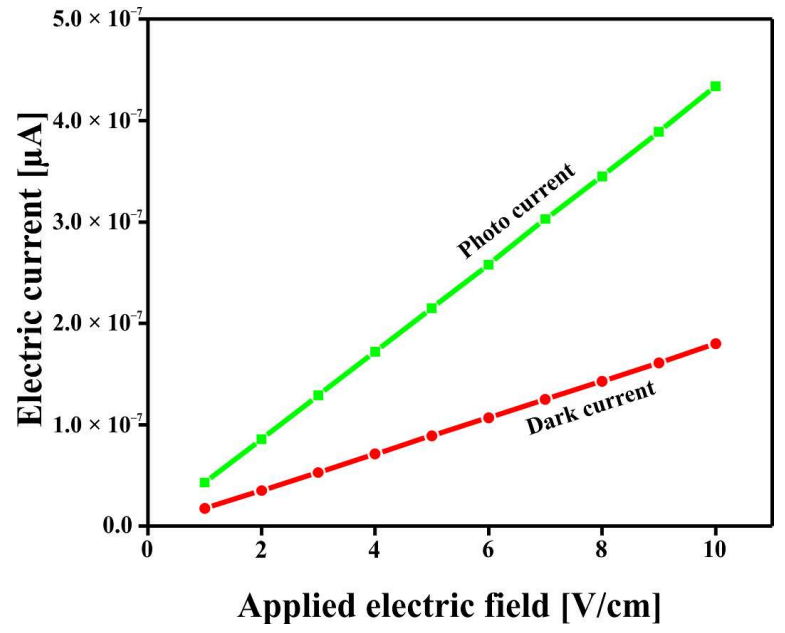

Fig. 7. The variation of field dependent dark current and photocurrent.

observed on the grown APAB crystal with water as an etchant and care had been taken to ensure that no microcrystals were present on the surface before being treated with the etchants.

Fig. 8 shows the etch pit patterns observed on the flat crystal face of APAB with an etching time of $7 \mathrm{~s}, 8 \mathrm{~s}$ and $10 \mathrm{~s}$, respectively. The patterns reveal square etch pits and these faces possess minimum four fold rotational symmetry. These results indicate that the crystal grown in the present study possesses better quality.

\subsection{FMO analysis}

The highest occupied molecular orbitals (HOMOs) and the lowest-lying unoccupied molecular orbitals (LUMOs) are the main orbitals named as frontier molecular orbitals (FMOs) which participate in the chemical stability. They play an important role in the optical and electric properties, as well as in quantum chemistry and UV-Vis spectra [20]. The HOMO that signifies the capability to donate an electron is directly related to the ionization potential, LUMO that as an electron acceptor embodies the ability to acquire an electron, is directly related to the electron affinity. The HOMO and LUMO energy calculated by $\mathrm{HF} / 6-31 \mathrm{G}$ method is given below [21]:

HOMO energy $=-0.19429 \mathrm{eV}$

LUMO energy $=-0.17704 \mathrm{eV}$

HOMO-LUMO energy gap, $\Delta \mathrm{E}=0.01725 \mathrm{eV}$
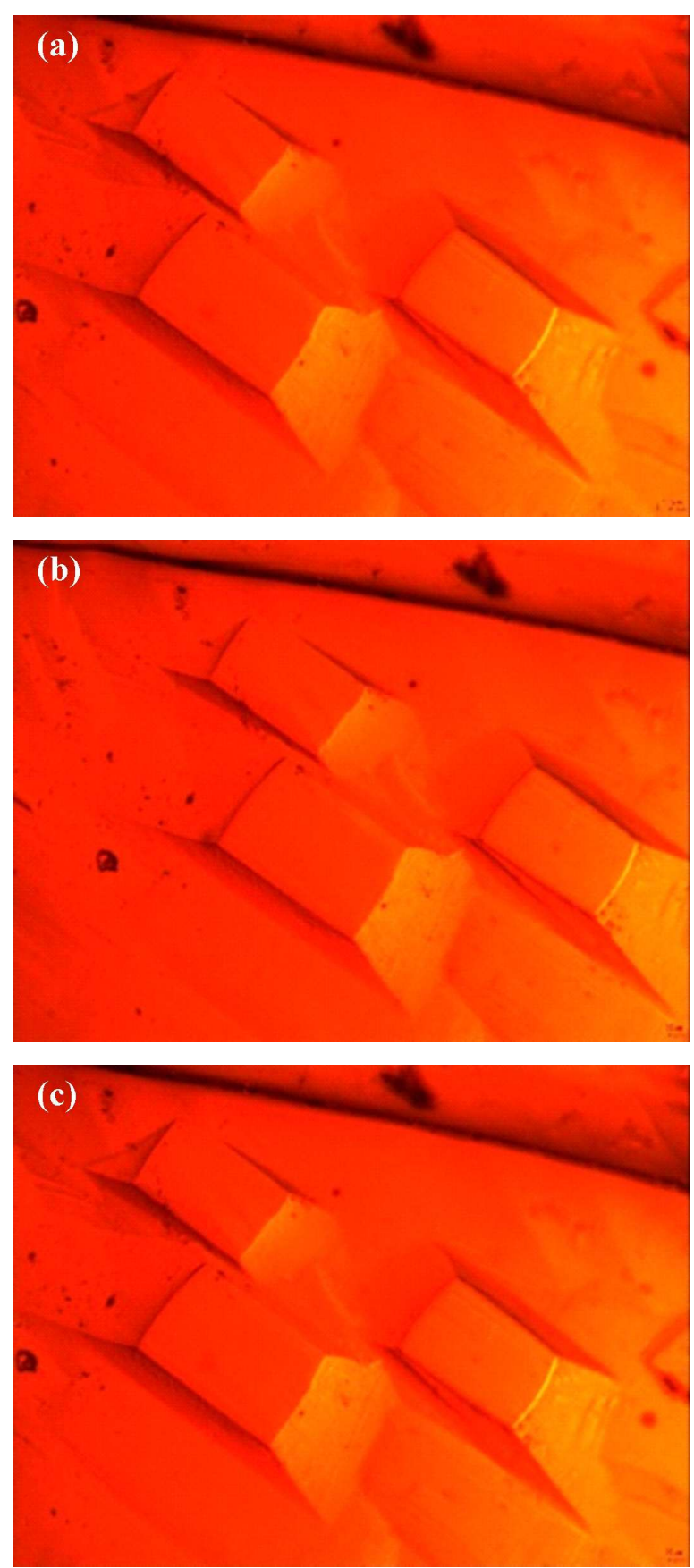

Fig. 8. Etching surfaces of APAB crystal.

The energy gap between HOMO and LUMO determines the kinetic stability, chemical reactivity, optical polarizability and chemical hardness/softness of a molecule [22, 23]. Since the energy gap of the APAB is found to be $0.01725 \mathrm{eV}$ it is more polarizable and termed as a soft molecule. 
HOMO and LUMO energy gap elucidates the eventual charge transfer interactions within the molecule (Fig. 9). The other calculated values such as ionization energy (IE), electron affinity (EA), global hardness (n), electronic chemical potential $(\mu)$ and global electrophilicity index $(\omega)$ for the title molecule are $0.12688,0.09213,0.017375$, -0.21901 and 1.38029 .

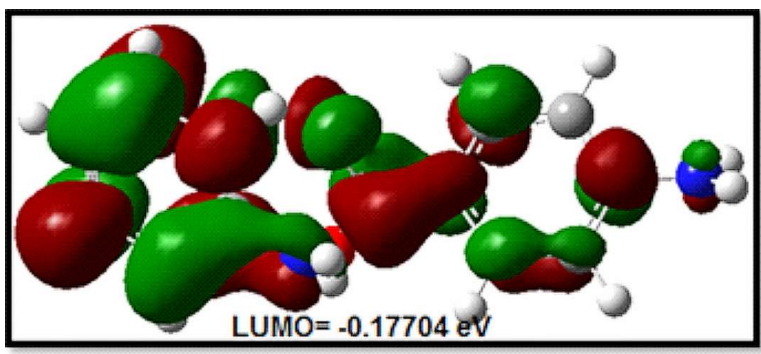

$$
\Delta E_{g}=0.01725 \mathrm{eV}
$$

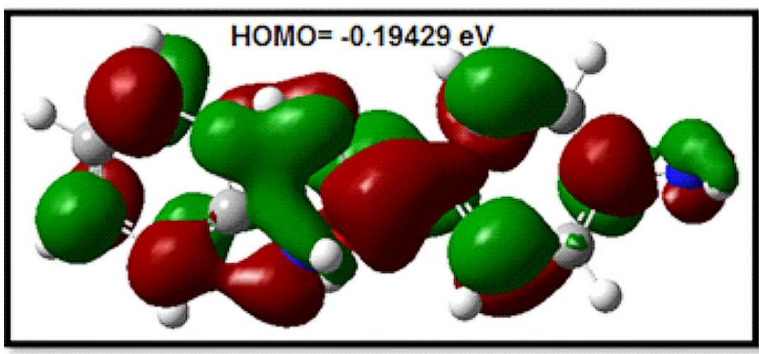

Fig. 9. HOMO-LUMO sketch of APAB crystal.

\subsection{Powder second harmonic generation}

The SHG property of the grown APAB crystals was examined through the modified Kurtz and Perry powder technique [24]. In this method, powdered samples with uniform particle size of $200 \mu \mathrm{m}$ to $220 \mu \mathrm{m}$ were tightly packed in a micro-capillary tube. The samples were then subjected to the output of Q-switched Nd:YAG laser emitting a wavelength of $1064 \mathrm{~nm}$ with the input power of $3.1 \mathrm{~mJ} /$ pulse. The beam was well focused on the sample and the output signal of $532 \mathrm{~nm}$ wavelength was generated. This reduction in the wavelength of input radiation by half confirms the second harmonic generation property. The green light intensity was registered by a photomultiplier tube and converted into an electrical signal which was then displayed on the oscilloscope screen. The SHG conversion

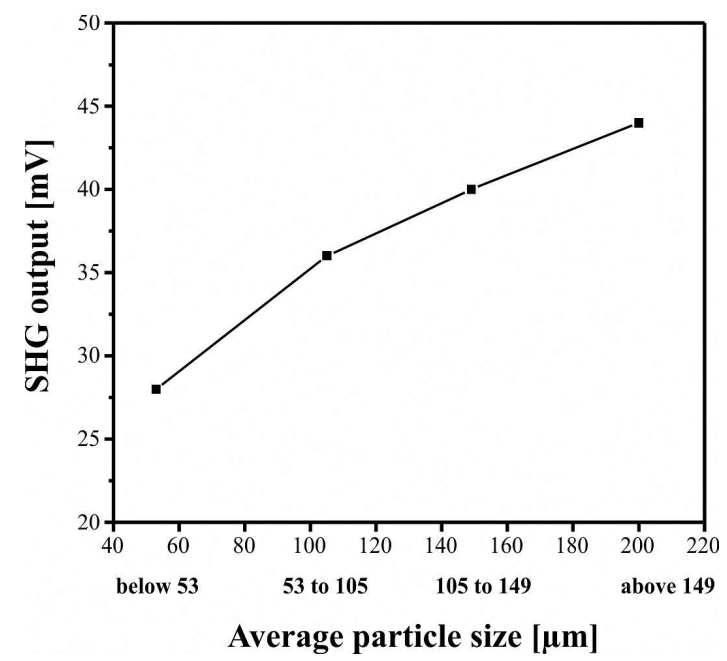

Fig. 10. The plot between average particle size and the second harmonic output values.

efficiency was computed by the ratio of the signal amplitude of the APAB sample to that of the KDP signal amplitude recorded for the same input power. The SHG efficiency of the grown APAB crystal $(44 \mathrm{mV})$ was found to be more than two times of that of KDP $(20 \mathrm{mV})$. In the earlier work, Arumanayagam et al. [9] found that APAB is 2.9 times higher than that of standard KDP. But in the present work it is only 2.2 times of that of KDP. Variation in the SHG output is attributed to the difference in the input power, because the SHG efficiency mainly depends on the input power as well as the particle size.

\subsection{Phase matching property}

To study the phase matching property of the APAB crystal, crystallites of various sizes were subjected to investigations using the KurtzPerry powder technique. Crystals of APAB were grounded and sieved into distinct particle size ranges, i.e. below $53 \mu \mathrm{m}, 53 \mu \mathrm{m}$ to $105 \mu \mathrm{m}, 105 \mu \mathrm{m}$ to $149 \mu \mathrm{m}$ and above $149 \mu \mathrm{m}$. The SHG efficiency of the crystals of different sizes was measured. A graph has been plotted between average particle size and the second harmonic output values (Fig. 10).

From the figure, it is observed that the SHG output increases as the particle sizes increase; beyond a certain size it attains its upper limit value. 
It reflects the attainment of the maximum output value of the crystallites. In the case of phasematchable materials it has been noted that beyond the coherence length $\left(l_{c}\right)$ the output efficiency reaches its limiting value. In this region, i.e. $\hat{r} \gg 1_{c}$, the phase matchable materials attain their maximum second harmonic intensity independent of the particle size [20]. This explains that the grown APAB crystal is a phase matching material.

\section{Conclusions}

The nonlinear optical single crystals of 2-aminopyridinium 4-aminobenzoate were synthesized and grown by adopting the slow evaporation technique at room temperature. The single crystal and powder X-ray diffraction analysis confirmed the non-centrosymmetry space group and crystallinity of the grown crystals. The presence of various functional groups in the crystal was analyzed by The FT-IR spectrum. The UV-Vis absorption analysis revealed the electron transition around the wavelength of $358 \mathrm{~nm}$ which confirms the formation of charge transfer in the grown crystal. The transparency of the grown crystals was studied through UV-Vis transmission spectra. The APAB crystal showed the transparency beyond the $400 \mathrm{~nm}$ wavelength (visible) region which is a desired property for various NLO applications. From the transmittance value, the optical band gap was calculated. The SHG efficiency of APAB was $44 \mathrm{mV}$ which is found to be more than two times that of KDP $(20 \mathrm{mV})$. The particle size dependence of SHG output illustrates that the crystals possess phase matching ability. The low value of birefringence indicates that the crystal can be used as a harmonic generation device. Small orbital energy gap confirms the energy transfer interaction within the crystal. The characteristic of low dielectric loss at high frequencies suggests that the grown crystal possesses enhanced optical quality with lesser defects. Hence, the grown crystal may be the best candidate for nonlinear optical (NLO) applications.

\section{Acknowledgements}

The authors gratefully acknowledge the financial support from the DST, Government of India, for the major research project (SB/EMEQ-293/2013). One of the authors, B. Babu, thanks UGC Networking Resource Centre, School of Chemistry, University of Hyderabad, India, for awarding Visiting Research Fellowship.

\section{References}

[1] Dalton L.R., Steier W.H., Robinson B.H., Zhang C., Ren A., Garner S., Chen A., Londergan T., Irwin L., Carlson B., Fifield L., PheLan G., Kincaid C., Amend J., Jen A., J. Mater. Chem., 9 (1999), 1905.

[2] Silambarasan A., Krishna Kumar M., ThirunaVukKarasu A., Mohan Kumar R., UMARAni P.R., J. Cryst. Growth, 420 (2015), 11.

[3] Kippelen B., Marder S.R., HendrickX E., MaLDONADO J.L., GUILlemet G., VOlOdin B.L., SteEle D.D., EnAmi Y., SANDAlPhon, YaO Y.J., WAng J.F., Rockel H., ERskine L., PeyghamBARIAN N., Science, 279 (1998), 54.

[4] Aditya Prasad A., Muthu K., Rajasekar M., MeEnatchi V., MeEnakshisundaram S.P., Spectrochim. Acta A, 135 (2015), 805.

[5] Oudar J., Hierle R., J. Appl. Phys., 48 (1977), 2699.

[6] Chandra L., Chandrasekaran J., Perumal K., BABU B., Optik, 127 (2016), 3206.

[7] Thirupugalmani K., Karthick S., SHANmugam G., Kannan V., Sridhar B., Nehru K., BrahadeEswaran S., Opt. Mater, 49 (2015), 158.

[8] Balaprabhakaran S., Chandrasekaran J., Babu B., Thirumurugan R., Anitha K., Spectrochim. Acta A, 136 (2015), 700.

[9] Arumanayagam T., Murugakoothan P., JMMCE, 10 (2011), 1225.

[10] Bis J.A., ZaworotKo M.J., Cryst. Growth Des., 5 (2005), 1169.

[11] Anie Roshan S., Joseph C., Ittyachen M.A., Mater. Lett., 49 (2001), 299.

[12] Venkataramanan V., Maheswaran S., Sherwood J.N., Bhat H.L., J. Cryst. Growth, 173 (1997), 605.

[13] Tigau N., Ciupinaa V., Prodana G., Rusub G.I., Gheorghies C., VAsilec E., J. Optoelectron. Adv. M., 6 (2004), 211.

[14] Chawla A.K., Kaur D., Chandra R., Opt. Mater, 29 (2007), 995.

[15] Bhoopathi G., Jayaramakrishnan V., RaViKUMAR K., PrasanyaA T., Karthikeyan S., Mater. Sci.-Poland, 31 (2013), 1.

[16] Hundelshausen von U., Phys. Lett. A, 34 (1971), 405.

[17] Babu B., Chandrasekaran J., BalaprabHAKARAN S., Optik, 125 (2014), 3005.

[18] Suresh Sagadevan, LAJPE, 6 (2012), 547.

[19] Joshi V.N., Photoconductivity, Marcel Dekker, New York, 1990.

[20] Varsanyi G., Assignments for Vibrational Spectra of Seven Hundred Benzene Derivatives, Vol. I, Adam Hilger, London, 1974. 
[21] Gaussian 09 Program, Revision C.01, FRISCH J., Trucks G.W., Schlegel H.B., Scuseria G.E., Robb M.A., Cheeseman J.R., Scalmani G., Barone V., Mennucci B., Petersson A., Nakatsuji H., Caricato M., Li X., Hratchian H.P., Izmaylov A.F., Bloino J., Zheng G., SONnEnberg J.L., HAdA M., Ehara M., TOYOTA K., FuKuda R., HASEgawa J., ISHidA M., Nakajima T., Honda Y., Kitao O., Nakai O., Vreven T., Montgomery J.A., Peralta J.E., Ogliaro F., Bearpark M., Heyd J.J., BrothERs E., Kudin K.N., Staroverov V.N., KeIth T., Kobayashi R., Normand J., Raghavachari K., RENDEll A., BURANT J.C., IYENGAR S.S., Tomasi J., Cossi M., Rega N., Millam J.M., Klene M., Knox J.E., Cross J.B. BAKKen V., Adamo C., Jaramillo J., Gomperts R., Stratmann R.E., Yazyev O., Austin A.J., CAmmi R., PoMelli C., OChTERSKI J.W., MARTIN R.L., Morokuma K., ZaKrzewski G., Voth G.A., SALVADOR P., DANNENBERG J.J., DAPPRICH S., Daniels A.D., Farkas O., Foresman J.B., OrTiZ J.V., Cioslowski J., Fox D.J., 2010. Gaussian, Inc., Wallingford CT.
[22] Bellamy L.J., The Infrared Spectra of Complex Molecules, $3^{\text {rd }}$ Ed., Wiley, New York, 1975.

[23] Koglin E., Witte E.G., Meier R.J., Vib. Spectrosc., 33 (2003), 49.

[24] Kurtz S.K., Perry T.T., J. Appl. Crystallogr., 9 (1968), 3798.
Received 2016-05-06 Accepted 2017-01-19 